\title{
A educação sanitária como profissão feminina"
}

\author{
Heloísa Helena Pimenta Rocha**
}

\begin{abstract}
Resumo
Tomando como ponto de partida o processo de institucionalização da educação sanitária em São Paulo, este artigo procura retraçar a trajetória de Maria Antonieta de Castro, profissional cuja atuação se confunde com a implementação de um novo modelo de intervenção em saúde pública, instituído pela Reforma Paula Souza em 1925. Por meio do exame da inserção dessa professora primária no campo da saúde pública, procura-se compreender a constituição de uma profissão que, lançando mão dos quadros do magistério, se configuraria em uma profissão predominantemente feminina.
\end{abstract}

Palavras-chave: História da Educação, Educação Sanitária, Saúde, Maria Antonieta de Castro, Educadoras Sanitárias.

\footnotetext{
* Recebido para publicação em fevereiro de 2005, aprovado em abril de 2005.

*** Faculdade de Educação, UNICAMP, Campinas-SP, Brasil. heloisah@unicamp.br 


\title{
Educação sanitária
}

\author{
Sanitary Education as a Female Profession
}

\begin{abstract}
Focusing the process of institutionalization of sanitary education in the state of São Paulo (Brazil), this article tries to outline the career of sanitary educator Maria Antonieta de Castro. Her professional performance intertwines with the implementation of a new intervention model in public health, instituted by the Paula Souza Reform in 1925. Analyzing the insertion of this primary teacher in the field of public health, it intends to understand the constitution of a profession that became a women's career.
\end{abstract}

Key Words: History of Education, Sanitary Education, Health, Maria Antonieta de Castro, Sanitary Educators. 
O extraordinário crescimento experimentado pela cidade de São Paulo, entre o final do século XIX e as décadas iniciais do XX, trouxe à cena um conjunto de problemas de dimensões até então desconhecidas. O intenso processo de urbanização, associado ao aumento do custo de vida, má distribuição de renda, baixos salários e altas taxas de desemprego, teve como reverso a eclosão de uma série de problemas que exigiam providências urgentes, dentre os quais figuram: fome, pobreza, péssimas condições de moradia, epidemias, além dos elevados índices de morbidade $e$ mortalidade infantil. Sanear a cidade, dotá-la de novos equipamentos, redefinir os usos dos espaços urbanos, estabelecer novos códigos de convivência e instituir novas condutas foram alguns dos desafios que se impuseram aos médicos-higienistas e sanitaristas, preocupados com a ordenação da cidade $e$ o disciplinamento dos seus habitantes.

Diante desses desafios, o engendramento e a difusão de novas formas de viver e novas práticas de cuidado do corpo, desenhadas de modo a garantir a participação ativa do indivíduo na manutenção de sua própria saúde, apresentaram-se, sobretudo a partir da década de 1920, como possibilidade de enfrentar esse amplo leque de problemas gerados pelo crescimento urbano $e$ pelo amontoamento da população pobre em determinadas regiões da cidade. Assumindo como eixo central a educação sanitária, a política de saúde pública se deslocou, no período, de um enfoque marcadamente policialesco para uma atuação calcada, prioritariamente, na formação da consciência sanitária da população, sem deixar de lado, entretanto, as práticas de inspeção sanitária vigentes. Deslocamento que se fez acompanhar da emergência de novos profissionais no campo da saúde, dentre os quais se destacam as educadoras sanitárias.

Tomando como ponto de partida o processo de institucionalização da educação sanitária em São Paulo, este artigo procura retraçar a trajetória da educadora sanitária Maria Antonieta de Castro, profissional cuja atuação se confunde com a implementação de um novo modelo de intervenção em saúde 
Educação sanitária

pública, instituído pela Reforma Paula Souza em 1925. Para tanto, lança mão de documentos que reúnem dados biográficos de Maria Antonieta e de algumas das teses apresentadas por ela em congressos realizados no final da década de $1920 .{ }^{1}$

Examinando a inserção dessa professora primária no campo da saúde pública, busca-se, ao mesmo tempo, compreender as representações que presidiram a constituição de uma profissão que, utilizando-se dos quadros do magistério primário, se configuraria em um espaço de atuação predominantemente feminino. Pondo em cena as representações sobre a figura da educadora sanitária e, por outro lado, dando visibilidade às práticas que permitiram levar a mensagem da higiene às crianças, professoras e mães, a trajetória de Maria Antonieta constitui-se numa entrada privilegiada para a compreensão de aspectos significativos do processo de institucionalização da educação sanitária.

\section{"Nos percalços de uma tarefa nova"}

Maria Antonieta Mendes de Castro nasceu em Itapetininga em 1892 e faleceu em São Paulo, em outubro de 1984. Concluiu o curso primário em sua terra natal, em 1904. Não se sabe em que ano e por que motivos mudou para São Paulo. ${ }^{2}$ Já na capital,

\footnotetext{
1 Agradeço às bolsistas de Iniciação Científica Daniela Cristina M. Cosso e Maria Cecília S. Augusto, pelo apoio na localização das teses apresentadas por Maria Antonieta nos congressos realizados pela Associação Brasileira de Educação e pela Sociedade Brasileira de Higiene. Sou muito grata, também, a Maria Lucia Mott, Olga Sofia F. Alves e Vera Regina B. Marques, pela leitura cuidadosa e pelas valiosas sugestões, que contribuíram para dar a este artigo a sua forma final.

2 Os dados biográficos de Maria Antonieta de Castro foram extraídos de documentos localizados no Centro de Memória da Saúde Pública/Faculdade de Saúde Pública/USP. Trata-se, em grande parte, de versões do Curriculum Vitae, algumas das quais elaboradas, provavelmente, por ocasião da tramitação dos projetos de outorga de títulos honoríficos, na Assembléia Legislativa do Estado de São Paulo e na Câmara Municipal de São Paulo, em 1965 e 1970, respectivamente. Os limites de fontes dessa natureza, que permitem ter acesso a
} 
diplomou-se na Escola Complementar e, em 1910, na Escola Normal de São Paulo, trajetória que se assemelha à de outras tantas mulheres, que encontraram no magistério uma das poucas possibilidades de dar continuidade aos estudos após a conclusão do ensino primário. Opção comum tanto para mulheres que precisavam trabalhar para garantir a sua sobrevivência e que pretendiam efetivamente lecionar, como para aquelas que buscavam se preparar para o casamento ou, ainda, para as que almejavam a profissionalização em outras áreas, uma vez que o magistério se configurou num dos únicos espaços de atuação profissional respeitável para as mulheres da classe média até pelo menos o final da década de $1930 .^{3}$

Concluído o curso, retornou ao interior do estado, onde atuou junto ao Grupo Escolar de Indaiatuba, sendo removida, em 1914, para o Grupo Escolar Oswaldo Cruz, na capital. Vale lembrar que as remoções das professoras, após os primeiros anos de exercício profissional, não se constituíam num fato incomum para a época: muitas eram as formas acionadas para retornar a São Paulo, onde provavelmente se encontravam melhores condições de vida e trabalho.

Em 1925, com 33 anos de idade e 14 de exercício profissional, a vida de Maria Antonieta tomaria uma nova direção. Atendendo ao convite do diretor geral da Instrução Pública, Pedro Voss, foi nomeada como educadora sanitária e comissionada junto ao Instituto de Hygiene de São Paulo, para a realização do recém-criado curso de educadores sanitários, deixando o

dados referentes à formação, atuação profissional, produção acadêmica, dentre outros, são evidentes quando se busca compreender os motivos que orientaram as escolhas pessoais e profissionais ou identificar o móvel das ações do sujeito cuja trajetória se pretende retraçar.

${ }^{3}$ Cf. BRUSCHINI, Cristina e AMADO, Tina. Estudos sobre mulher e educação: algumas questões sobre o magistério. Cadernos de Pesquisa (64), São Paulo, 1988, pp.4-13; DEMARTINI, Zeila de Brito F. e ANTUNES, Fátima Ferreira. Magistério primário: profissão feminina, carreira masculina. Cadernos de Pesquisa (86), São Paulo, 1993, pp.5-14. 
Educação sanitária

magistério primário. A criação desse curso, que representou a possibilidade de reorientação profissional para todo um grupo de professoras dessa geração, deve ser compreendida no âmbito das propostas modernizadoras de intervenção no campo da saúde pública implementadas em São Paulo na década de 1920.

Instituído pelo Decreto 3.876 que reorganizou o Serviço Sanitário de São Paulo, o curso consubstanciou-se numa das expressões da política de saúde pública implantada pelo sanitarista Geraldo de Paula Souza, então diretor do Instituto de Hygiene e do Serviço Sanitário de São Paulo, em conformidade com os moldes norte-americanos aprendidos em seu curso de doutoramento, realizado junto à Universidade de Johns Hopkins, em Baltimore. ${ }^{4}$ Concebendo os problemas de saúde como resultado da falta de educação $e$, nessa medida, atribuindo à educação sanitária a possibilidade de superação dos graves problemas gerados pelo crescimento urbano, a reforma sanitária de 1925 teve na criação do curso de educadores sanitários e dos centros de saúde as suas principais inovações. ${ }^{5}$

4 Para um estudo mais aprofundado sobre o processo de criação do Instituto de Hygiene, como parte de um acordo entre o governo do Estado e a Fundação Rockefeller, e seu papel na definição dos rumos da política sanitária paulista no período, consultar RocHA, Heloísa Helena Pimenta. A higienização dos costumes: educação escolar e saúde no projeto do Instituto de Hygiene de São Paulo (1918-1925). Campinas/São Paulo, Mercado de Letras/FAPESP, 2003.

5 Criado em 1925, o curso de educadores sanitários foi extinto em 1962, após um longo período de discussões e embates, iniciados em 1948, por ocasião da promulgação do Estatuto do Funcionalismo Público, no qual a carreira de educador sanitário não foi contemplada, por não se tratar de uma profissão que exigisse formação em nível superior. A Associação de Educação Sanitária, tendo à frente Thereza Filardi, teve uma importante atuação no sentido de lutar pelo enquadramento da carreira no grupo de Cargos de Serviços Técnicos. A exigência de formação em nível secundário como requisito para o ingresso justificou o reconhecimento do curso de educadores sanitários, pelo Conselho Nacional de Educação, em 1959, como curso de nível superior. O reconhecimento pelo conselho redundou na decisão da faculdade de suspendê-lo por prazo indeterminado, a partir de 1962. Sobre a criação do curso, cf. Decreto 3.876, de 26 de julho de 1925. Collecção das leis e decretos do Estado de São 
Dispondo sobre os objetivos, critérios de seleção, currículo e formas de avaliação, o regulamento do curso, aprovado em 1926, previa a formação de novos "auxiliares de saúde pública", ${ }^{6}$ saídos das fileiras do magistério público, cuja atuação deveria possibilitar a ampliação do alcance da obra de difusão dos conhecimentos de higiene. ${ }^{7}$ Instituindo práticas que visavam impressionar $e$ convencer da importância dos hábitos de higiene, em espaços que iam dos recém-criados centros de saúde, escolas, hospitais, fábricas até as próprias casas, as iniciativas encetadas pelas educadoras sanitárias tinham na infância o seu alvo prioritário. Entretanto, nem só as crianças deveriam se constituir em objeto de atenção desses profissionais. Por intermédio delas, procurava-se atingir suas famílias, ensinando-lhes um padrão de vida considerado civilizado, expresso em práticas desejáveis de asseio pessoal e do vestuário, higiene do lar, alimentação e cuidados com os filhos.

A criação do curso não se deu sem contestações $e$ resistências. Considerada por alguns parlamentares como "fantasia teórica", a proposta de formação de educadoras

Paulo. São Paulo, 1925, pp.398-474. Em relação aos embates que culminaram com a sua suspensão, cf. CANDEIAS, Nelly Martins F. Evolução histórica da educação em saúde como disciplina de ensino na Faculdade de Saúde Pública da Universidade de São Paulo - 1925 a 1967. Revista de Saúde Pública (22), São Paulo, 1988, pp.345-367.

${ }^{6}$ A terminologia é utilizada em documentos do período para se referir não apenas às educadoras sanitárias, mas também às enfermeiras de saúde pública, visitadoras sanitárias, técnicos de laboratório, inspetores sanitários, guardas, dentre outros profissionais, cuja atuação subsidiava o trabalho dos médicos $e$ técnicos especializados.

7 Embora o curso de educadores sanitários não se destinasse exclusivamente a mulheres, a matrícula de homens só se verificou a partir de 1927, mantendo-se, ao longo dos anos, bastante inferior em relação à das mulheres. Só para se ter uma idéia, dos 130 alunos que se matricularam entre 1925 e 1930, aproximadamente $83 \%$ eram mulheres e $17 \%$ homens. Cabe notar que, apesar da ausência de restrições quanto à admissão de homens e da efetiva matrícula de professores e diretores, não é incomum nos documentos a referência ao curso e à profissão no feminino. 
Educação sanitária

sanitárias foi alvo de duras críticas, que procuravam assinalar a incapacidade desses "auxiliares de saúde" para o desempenho das tarefas que lhes caberiam:

querer-se agora dar educação sanitária por meio de conferências, feitas por médicos, acadêmicos e uma nova entidade que são os educadores, educadores especializados ou simples educadoras. Estes serão professores que, depois de um curso de um ano praticado no Instituto de Higiene, irão fazer - não fazer bem o que, porque não sendo médicos, não tendo educação especializada, pouco ou muito pouco poderão fazer. ${ }^{8}$

Críticas em relação ao novo modelo de intervenção em saúde pública? Desconfiança em relação à insuficiência da formação? Ou desconfiança em relação à capacidade das mulheres para assumir responsabilidades na esfera pública?

Nos primeiros dias do mês de dezembro de 1927, o nome de Maria Antonieta figura nas páginas do Correio Paulistano, que publica, na íntegra, o discurso proferido na cerimônia de formatura da primeira turma do curso de educadores sanitários. Falando entusiasticamente, a formanda remete às apreensões e ao arrebatamento que marcaram o momento de ingresso no curso $e$ de redirecionamento da trajetória profissional das 16 professoras primárias escolhidas para compor essa primeira turma:

Faz três anos hoje. Estávamos nos percalços de uma tarefa nova, de uma atividade outra que aquela a que nos acostumaram às lides do magistério.

Íamos alistar-nos em uma cruzada nova! De ânimo forte, com um entusiasmo grande a nos borbulhar dentro d'alma, com uma vontade imensa de acertar, de fazer jus à distinção com que nos honrara o convite do então diretor geral da Instrução Pública, o eminente educador Pedro Voss.

8 Apud CANDEIAS, N.M.F. Evolução histórica da... Op. cit., pp.349-350. 
Heloísa Helena Pimenta Rocha

Iríamos, em breve, não mais guiar a nossa infância pelos meandros do ler $e$ do escrever, mas ensinar a todos $e$ por toda a parte o a b c da Saúde!

Iríamos, num apostolado sublime, pregar o Evangelho, mercê do qual toda a gente aprendesse a ser forte, e sendo forte pudesse trazer a sua contribuição para o engrandecimento e o progresso de nossa terra paulista.

Iríamos, em suma, pôr nossa dedicação, nossos esforços, toda a força da nossa boa vontade ao serviço da Saúde Pública, colocar nossa pedra no grande edifício do revigoramento da raça brasileira. (...)

Como, porém, fazer chegar ao povo os benefícios da higiene?

Pela educação sanitária.

Era a solução do problema! Pela educação sanitária, que, segundo Metcknikof, "deve ser colocada em lugar de destaque entre os ramos da moral aplicada" (...)

Os professores seriam os agentes divulgadores da higiene entre as classes populares... ${ }^{9}$

O convite, a opção entre as "lides do magistério" e a difusão do "abc da saúde", o alistamento à "nova cruzada" são elementos que se articulam na produção desse momento inaugural na trajetória das educadoras sanitárias. Em seu discurso, fortemente marcado pelo apelo religioso e atravessado por representações da mulher como um ser angelical, dotado de características inatas que a orientavam para o cuidado da infância, Maria Antonieta convoca os ouvintes a testemunharem o devotamento, o esforço $e$ a boa vontade com que as formandas se haviam dedicado ao curso e, ao mesmo tempo, conclama as companheiras a abraçar o desafio que se colocava à sua frente; desafio esse que se consubstanciava na "missão apostólica" de propalar os preceitos de higiene, contribuindo decisivamente no "revigoramento da raça brasileira". Invocando os luminares da "moderna ciência da

9 Discurso proferido pela formanda Maria Antonieta de Castro. Correio Paulistano, São Paulo, 9/12/1927. 
Educação sanitária

higiene", o discurso procura legitimar a atuação das novas "missionárias", vinculando-a aos supremos ideais da civilização $e$ do progresso.

Saúde, instrução e moral constituíam o tripé sobre o qual se deveria alicerçar a atividade dessas "mensageiras da saúde", incumbidas do "sublime apostolado" de levar a todos os cantos a boa nova da "regeneração da raça". "Ensinar a todos e por toda a parte $\mathrm{O}$ abc da saúde", empenhando-se na obra de aperfeiçoamento físico, intelectual e moral, consubstanciava-se, desse modo, na "nova cruzada" em que se alistavam agora essas mulheres experimentadas na tarefa de "guiar a infância pelos meandros do ler e do escrever". Levando o "evangelho da saúde" a crianças, jovens e velhos e chamando-os, com a "doçura da sua fala", à conversão à "religião da higiene", as educadoras sanitárias estariam cumprindo a "missão" para a qual foram convocadas: de contribuir, pela formação de homens fortes, cultos e virtuosos, para o engrandecimento do Brasil e o seu nivelamento com a "vanguarda da Civilização".

Possibilidade de difusão dos benefícios da higiene ao povo, a educação sanitária é metaforizada como uma semente, a cujo cuidado as educadoras vinham se dedicando durante toda a sua formação, já podendo, inclusive, antever os primeiros frutos. $\mathrm{O}$ momento da conclusão do curso constituía-se, dessa forma, numa oportunidade privilegiada para lançar um olhar sobre a obra profícua desenvolvida no tempo de formação, certeza de um futuro promissor que se anunciava:

Temos consciência do nosso dever bem cumprido. É justo, pois, que hoje nos detenhamos, um pouco, na encosta da colina. Olhemos para trás. O terreno vem sendo preparado. A sementeira vem sendo feita. Aqui e além, tufos de folhagem verde vêm aparecendo. A seara promete. E se o nosso próprio emblema o diz: "a educação sanitária 
Heloísa Helena Pimenta Rocha

semeia, a raça colherá os frutos", promissora será a colheita de amanhã. ${ }^{10}$

O emblema estampado no diploma traduzia os ideais de "regeneração da raça" que perpassariam as várias frentes de atuação em que se engajaram as educadoras sanitárias, sob a firme orientação de Maria Antonieta. Movidas pelo lema "A educação sanitária semeia, a raça colherá o fruto", as suas iniciativas deveriam contribuir para fazer brilhar e resplandecer "o sol da saúde". Qual jardineiras, a elas cabia preparar o terreno e "semear" a consciência sanitária, visando obter a farta colheita de uma raça redimida do "pecado da miscigenação".

$\mathrm{O}$ redirecionamento que o ingresso nesse curso representou na trajetória de Maria Antonieta situa-se no contexto das possibilidades de atuação profissional franqueadas às mulheres no período. Assim, se a opção pela educação sanitária significou uma mudança do campo educacional para o campo da saúde pública, tal mudança não se consubstanciou num afastamento das atividades ligadas à socialização das crianças e ao cuidado; tarefas que, historicamente, foram sendo consideradas como ocupações femininas, espécie de extensão das atividades domésticas, parte das funções maternas que cabiam às mulheres. Tornar-se educadora sanitária representou, desse modo, a inserção em um espaço de atuação profissional que foi se constituindo em continuidade ao magistério, o qual, desde a virada do século, vinha se tornando uma profissão predominantemente feminina.

Cabe lembrar que a feminização do magistério no Brasil tem suas origens ligadas à expansão do ensino público primário, no final do século XIX, momento em que os homens, atraídos pelas oportunidades de trabalho geradas pela urbanização $e$ industrialização, passam a deixar as salas de aula, as quais são ocupadas por um contingente cada vez mais significativo de mulheres. Fenômeno esse evidenciado pelo Censo Demográfico

${ }^{10}$ Discurso proferido pela formanda Maria Antonieta de Castro. Op. cit. 
Educação sanitária

de 1920, que registrou um percentual superior a $70 \%$ de mulheres no ensino público primário brasileiro, interpretado por educadores do período como uma "crise de homens no magistério público". ${ }^{11}$

O processo de feminização do magistério se fez acompanhar de péssimas condições de trabalho, rebaixamento salarial $e$ estratificação sexual da carreira docente, como assinala Cláudia Vianna. ${ }^{12}$ Esses aspectos são também registrados por Zeila Demartini e Fátima Antunes, cujas análises oferecem importantes elementos para a compreensão do processo por meio do qual os homens que permaneceram no magistério foram alçados aos postos de controle e formação de novos profissionais, conquistando melhor remuneração e status, num movimento de ascensão para o qual contaram não apenas os méritos profissionais e o fato de serem homens, mas também os bons relacionamentos que mantinham com os chefes políticos locais. Constituíam-se, desse modo, exceções as mulheres que obtiveram projeção e reconhecimento, conquistados não em função de apoios familiares ou políticos, mas à custa da longa experiência acumulada ou da obtenção de conhecimentos especializados, por meio da realização de cursos, dentre os quais o de educação sanitária. Tais elementos permitem a essas autoras concluir que o magistério se tornou uma profissão feminina e mal remunerada, porém uma "carreira masculina". ${ }^{13}$

Nesse sentido, é importante interrogar acerca das representações produzidas no âmbito desse processo, que

\footnotetext{
${ }^{11}$ A expressão é de Lourenço Filho e se refere ao significativo crescimento do número de mulheres formadas pela Escola Normal, em São Paulo, acompanhado do decréscimo do número de homens. Apud Louro, Guacira Lopes. Mulheres na sala de aula. In: PriORE, Mary del. (org.) História das mulheres no Brasil. 3. ed. São Paulo, Contexto, 2000, p.452.

${ }^{12}$ Vianna, Cláudia Pereira. O sexo e o gênero na docência. Cadernos Pagu (17/18), Campinas-SP, Núcleo de Estudos de Gênero-Pagu/Unicamp, 2001/02, pp.81-103.

${ }^{13}$ Demartini, Z.B.F. e AntunES, F.F. Magistério primário: profissão... Op. cit., p.13.
} 
redundou na constituição do magistério em um espaço de atuação predominantemente feminino. Como advertem Diana Vidal e Marília Carvalho, a feminização do magistério não pode ser lida como uma simples mudança na composição sexual do corpo docente, fazendo-se necessário atentar para as profundas transformações nos significados sociais atribuídos à docência, que responderam pela identificação da figura da professora a um conjunto de atributos ligados ao feminino e à maternidade. Segundo as autoras,

a questão central quanto ao magistério seria que sua feminização não significou apenas a entrada de mulheres na ocupação de professora, mas também um processo de deslocamento de significados - de escola, ocupação, ensino, mulher, feminilidade, maternidade, masculinidade, criança entre outros - que resultou na contigüidade observada hoje entre as representações de mulher, mãe e professora primária. ${ }^{14}$

A consideração desses elementos que se referem à feminização do magistério, compreendida como um processo complexo que envolveu não apenas mudanças na composição sexual do corpo docente, mas todo um conjunto de transformações nas representações acerca da docência, mostra-se fundamental quando se estuda a constituição de uma profissão que recrutou os seus quadros dentre experientes profissionais do magistério.

Aluna da primeira turma, Maria Antonieta de Castro se destacou, sendo designada assim que concluiu o curso, em 1927, para o cargo de educadora sanitária chefe da Inspetoria de Educação Sanitária e Centros de Saúde (IESCS), órgão criado pela

\footnotetext{
${ }^{14}$ VIDAL, Diana Gonçalves e CARVALHO, Marília Pinto. Mulheres e magistério primário: tensões, ambigüidades e deslocamentos. In: VIDAL, Diana Gonçalves e Hilsdorf, Maria Lúcia S. (orgs.) Brasil 500 anos: tópicas em história da educação. São Paulo, Edusp, 2001, p.212.
} 
Educação sanitária

reforma de 1925, como dependência da Diretoria Geral do Serviço Sanitário, com o objetivo de "promover a consciência sanitária da população". Investida da autoridade que o cargo lhe conferia, a educadora sanitária responsabilizou-se pela implementação $e$ direção das atividades desse corpo profissional, nos três centros de saúde da capital paulista e nas escolas primárias.

No conjunto dessas atividades, merecem destaque a implantação de cozinha de dietética, serviço domiciliário, "Escola de Saúde" para desnutridos; montagem de exposições de puericultura e educação sanitária; organização de campanhas educativas, concursos de robustez infantil, "Escola de Mãezinhas" (para o ensino de puericultura às alunas do quarto ano dos grupos escolares), curso popular de puericultura, além da elaboração de impressos de propaganda sanitária. A implementação desse amplo leque de atividades teve, certamente, um importante papel na legitimação desse novo modelo de intervenção no campo da saúde pública em São Paulo, que privilegiava a educação sanitária como forma de preservação da saúde e prevenção de doenças. O dinamismo com que se dedicou a essas atividades parece ter justificado a manutenção da educadora sanitária no cargo de direção, nas sucessivas reformas pelas quais passou essa inspetoria na década de 1930, as quais responderam pela vinculação de tal órgão ora à administração sanitária, ora à esfera da educação.

O papel coordenador exercido por Maria Antonieta não se limitou à sua atuação nas esferas estatais de institucionalização da educação sanitária, alargando-se por meio da liderança assumida na criação da Associação de Educação Sanitária, em 1930, da qual seria eleita primeira presidente. Os propósitos a que respondia essa entidade, a um só tempo corporativa e assistencial, podem oferecer uma dimensão das fronteiras em que foi se delineando a atuação das educadoras sanitárias, fronteiras essas que aproximavam saúde, educação e filantropia. Assim, a defesa dos interesses de classe era apenas um dos objetivos que orientaram a criação da entidade. Ocupando um lugar não menos 
importante, figurava como mote dessa iniciativa o objetivo de auxiliar os poderes públicos no combate à mortalidade infantil.

As iniciativas que redundaram na criação dessa associação sugerem que a educação sanitária foi se organizando de modo distinto do magistério, profissão na qual as entidades de defesa $e$ assistência da categoria foram se constituindo em espaços de atuação masculina. ${ }^{15}$

As preocupações com a mortalidade infantil e os intentos de oferecer elementos para a definição de políticas de assistência a crianças e mulheres pobres, que perpassaram a iniciativa de criação desta Associação, podem ser indicativas de sua maior aproximação com as entidades filantrópicas, criadas no período, que dos espaços de luta pela defesa dos interesses de classe dos professores. Criada e presidida por mulheres, a associação tinha como um dos seus objetivos o enfrentamento de um grave problema social, a mortalidade infantil, não se devendo perder de vista os objetivos de auxílio e, quiçá, de orientação ao Estado na definição de estratégias de ação.

As preocupações em relação à higienização da infância assumiram um lugar central na atuação de Maria Antonieta como educadora sanitária. Assim, em 1931, vamos encontrá-la comissionada junto ao Instituto Pedagógico de São Paulo, trabalhando em colaboração com o Serviço de Psicologia Aplicada no levantamento de medidas antropométricas, índices de nutrição e na realização de inquéritos sobre alimentação dos escolares, ao mesmo tempo em que difundia tais práticas aos

\footnotetext{
${ }^{15}$ Cabe registrar, nesse sentido, a criação de duas entidades voltadas para a defesa dos interesses do professorado: a Associação Beneficente do Professorado Público de São Paulo, em 1901, e o Centro do Professorado Paulista, em 1930, que resultou da articulação de eminentes professores, investidos em cargos de direção e inspeção, incorporando a antiga associação. CATANI, Denice Bárbara; VICENTINI, Paula Perin e LUGLI, Rosário S. Genta. O movimento dos professores e a organização da categoria profissional: estudo a partir da imprensa periódica educacional. In: CATANI, Denice Bárbara e BASTOS, Maria Helena C. (orgs.) Educação em revista: a imprensa periódica e a História da Educação. São Paulo, Escrituras, 1997, p.84.
} 
Educação sanitária

futuros professores, por meio de cursos de Antropometria Pedagógica. Provavelmente, a repercussão desse trabalho resultou no convite, por parte do diretor do Ensino, Sud Menucci, para assumir a direção do Serviço de Antropometria Pedagógica, onde permaneceu entre 1932 e 1933, realizando pesquisas sobre alimentação, peso e altura dos alunos das escolas de São Paulo.

A experiência consolidada ao longo da sua atuação como educadora sanitária se expressaria nas teses apresentadas à Escola Livre de Sociologia e Política, entre 1933 e 1934: Serviço Social valor, finalidades e métodos, na cadeira de Sociologia Geral; Peso e altura dos escolares de São Paulo, na cadeira de Estatística, tese elaborada com base nos dados de cerca de 8 mil alunos de 7 a 14 anos, matriculados nos grupos escolares da capital, coletados com o auxílio de 30 educadoras sanitárias, durante o período de atuação no Serviço de Antropometria Pedagógica.

A trajetória profissional de Maria Antonieta foi marcada por um intenso e pertinaz trabalho de divulgação da educação sanitária, o que pode ser constatado tanto pelas suas iniciativas ligadas à formação de educadoras sanitárias e professores - para os quais ministrou cursos, palestras e seminários sobre higiene escolar, educação sanitária e puericultura - , como pela sua produção, divulgada em periódicos nacionais e internacionais, congressos e conferências. Os propósitos de divulgação do trabalho desenvolvido na IESCS e de aperfeiçoamento profissional responderiam pelas viagens de estudos a vários estados brasileiros, como também à Argentina, Uruguai, Europa e Estados Unidos. Nesse sentido, pode-se afirmar que a sua atuação não se limitou ao cumprimento das exigências de um cargo administrativo, mostrando-se fundamental na implementação da reforma sanitária de 1925. Para além da implantação da inspetoria, chama a atenção a preocupação da educadora sanitária com o aperfeiçoamento profissional, como também com o aprimoramento das atividades desenvolvidas no âmbito desse órgão, por meio da pesquisa, publicação e divulgação dos seus trabalhos em alguns dos mais importantes fóruns de discussão do 
período, devendo-se destacar, nesse sentido, a sua ativa participação nas Conferências Nacionais de Educação, promovidas pela Associação Brasileira de Educação (ABE). ${ }^{16}$

Como se pode depreender da iniciativa que redundou na criação da Associação de Educação Sanitária, a educadora sanitária também participou ativamente de empreendimentos voltados para a assistência à infância pobre. Merece destaque, nesse sentido, o envolvimento com a Cruzada Pró-infância, cujas origens se ligam à sua atuação como educadora sanitária, em contato com o drama da falta de recursos para a aquisição de remédios e leite para os filhos das mulheres que acorriam aos centros de saúde. Como presidente da Associação, iniciou uma ampla campanha de arrecadação de donativos para as mães, recorrendo a Pérola Byington para solicitar-lhe apoio. ${ }^{17}$ Do diálogo entre ambas, resultou a criação, no âmbito dessa entidade, de uma Comissão de Combate à Mortalidade Infantil, da qual se originou a Cruzada Pró-infância. ${ }^{18}$ Assumindo cargos

\footnotetext{
${ }^{16}$ Sobre a criação da Associação Brasileira de Educação e sua importância no movimento educacional da década de 1920, cf. CARVAlHo, Marta Maria C. Molde nacional e fôrma cívica: higiene, moral e trabalho no projeto da Associação Brasileira de Educação. Bragança Paulista, Edusf, 1998.

${ }^{17}$ Referindo-se ao papel de Pérola Byington na organização inicial da Cruzada Pró-infância, Maria Lucia Mott destaca "Pérola Byington trouxe a experiência adquirida junto à Cruz Vermelha americana e brasileira, a boa relação com as elites, recursos financeiros da família". MOTT, Maria Lucia. Uma reflexão a partir da biografia de Pérola Byington. Gênero, Revista Transdisciplinar de Estudos de Gênero (2), Niterói, Universidade Federal Fluminense, 2003, pp.7-20.

${ }^{18}$ Maria Antonieta teve uma atuação destacada nessa entidade, tendo participado tanto da elaboração dos estatutos, como da organização das primeiras unidades: dispensário infantil, cozinha de dietética, casa maternal, escola de saúde no Parque D. Pedro, biblioteca infantil, "Pequeno Lar". Durante a segunda guerra, em 1942, participou da organização de restaurantes populares, centros para mulheres, centros de nutrição e berçários. Visando mobilizar a opinião pública em relação aos problemas vivenciados pelas crianças, elaborou, em 1930, o programa Semana da Criança, oficializado em 1939 pelo Departamento Nacional da Criança. Deve-se assinalar a convergência entre as
} 
Educação sanitária

de direção, desde a fundação, Maria Antonieta tornou-se diretora geral da Cruzada Pró-infância, a partir de 1963, com o falecimento de Pérola Byington.

Cabe lembrar que as preocupações com a assistência social, traduzidas em iniciativas voltadas para a proteção à infância $e$ à maternidade, figuram como um dos traços característicos da atuação das mulheres da elite e das camadas médias da sociedade no período. Distintamente das análises que vêm interpretando a presença significativa dessas mulheres no âmbito das redes de ação beneficente como álibi para ter acesso à esfera pública, alguns estudos biográficos têm contribuído no sentido de pensar a participação nas entidades filantrópicas como uma forma que elas encontraram para exercer a cidadania. Nesse sentido, examinando a trajetória de Pérola Byington, Maria Lucia Mott destaca:

diletantismo, falta de compromisso e álibi para ter acesso à esfera pública são palavras que certamente não identificam a relação que Pérola Byington teve com a Cruzada Pró Infância. Seu trabalho foi de dedicação exclusiva, profissional (embora não recebesse salário), com programa, metas, projetos de longo prazo. ${ }^{19}$

Semelhante dedicação e profissionalismo também se evidenciam quando se examina a trajetória da educadora sanitária Maria Antonieta de Castro, desautorizando possíveis leituras que procurem inserir as suas iniciativas nos quadros das estratégias de acesso à esfera pública.

iniciativas encetadas no âmbito da Cruzada e as que Maria Antonieta já vinha implantando como educadora sanitária chefe nas esferas estatais.

${ }^{19}$ MotT, Maria Lucia. Uma reflexão... Op. cit. Sobre o papel das mulheres na criação de associações filantrópicas e o papel dessas entidades na profissionalização das mulheres e na prestação de serviços para a população pobre, vale a pena conferir o artigo dessa mesma autora, publicado neste dossiê Gênero, medicina e filantropia: Maria Rennotte e as mulheres na construção da nação. 
Heloísa Helena Pimenta Rocha

\section{"A educação sanitária semeia, a raça colherá o fruto"}

A "cruzada da saúde" a que se lançaram as educadoras sanitárias, tendo à frente a figura de Maria Antonieta, desdobrouse num amplo rol de ações que incluiu, entre as décadas de 1920 e 1950, campanhas educativas de alimentação e campanhas contra doenças como peste bubônica, raiva, tuberculose, gripe asiática $e$ febre amarela; Semana de Educação Sanitária e Semana Antialcoólica; cursos de puericultura; concursos de robustez infantil; exposições de educação sanitária e puericultura; demonstrações de cultura física.

No cuidadoso trabalho de difusão das noções de higiene, há que se registrar a produção de numerosos impressos, dentre os quais podemos citar os dois livros infantis de autoria de Maria Antonieta de Castro - Papagaio Louro e Óculos de Mirianto -, além da utilização de modernos e ágeis meios de comunicação, como os filmes educativos e o rádio. Sob o pseudônimo de Mirianto, ela povoaria o imaginário infantil com uma série de contos, "com finalidade de propaganda sanitária", transmitida pela Rádio Educadora Paulista, em 1927, e conclamaria as famílias e os educadores a refletirem sobre temas como $O$ alcoolismo na infância e A criança que estuda, na década de 1930.

As preocupações em relação à higiene, puericultura, educação sanitária $e$ assistência à infância mesclaram-se em sua atuação, decisiva, como se pode perceber, na institucionalização da reforma sanitária de 1925. Presença marcante nos mais importantes fóruns de discussão das questões de saúde $e$ educação das décadas de 1920 e 1930, participou das Conferências Nacionais de Educação, apresentando a tese Do ensino de puericultura e a conferência $A$ escola $e$ a educação sanitária, na II Conferência (Belo Horizonte, 1928), e a tese Escola de saúde, na III Conferência (São Paulo, 1929). Participou da Conferência Nacional de Proteção à Infância (Rio de Janeiro, 1933), com a tese $O$ ensino da puericultura nas escolas $e$ agremiaçóes femininas. No I Congresso Brasileiro de Eugenia (Rio 
Educação sanitária

de Janeiro, 1929), discutiu $A$ influência da educação sanitária na redução da mortalidade infantil e, no $\mathrm{V}$ Congresso Brasileiro de Higiene, promovido pela Sociedade Brasileira de Higiene (Recife, 1929), tematizou as relações entre Puericultura e mortalidade infantil.

A temática da "regeneração da raça", enunciada enfaticamente no discurso de formatura, se manterá como eixo das teses apresentadas pela educadora sanitária nesses congressos, perpassando as epígrafes, a narrativa das ações e os significados atribuídos a elas. Falando como chefe da IESCS, num tom marcadamente institucional, Maria Antonieta faz da participação nesses eventos oportunidade de divulgação dos trabalhos ali desenvolvidos.

$\mathrm{Na}$ II Conferência Nacional de Educação, a sua tese obteve aprovação da Comissão de Educação Sanitária, que ressaltou a importância da sua contribuição e recomendou a publicação das conclusões. Defendendo a necessidade de difusão das noções de puericultura nas escolas primárias, seu discurso é extremamente sugestivo das representações em relação às mulheres pobres, que perpassam a atuação das educadoras sanitárias, como evidenciam suas conclusões:

A ignorância das mães sobre as noções de puericultura é uma das causas da mortalidade infantil.

As noções de puericultura devem ser ministradas desde os últimos anos da escola primária.

É de grande necessidade a disseminação dos cursos de puericultura por todo o Brasil, como uma das medidas que se impóem para a melhoria da saúde da criança brasileira. $^{20}$

\footnotetext{
${ }^{20}$ Parecer da Seção de Educação Sanitária. In: SiLVA, Arlette Pinto O. (org.) Páginas da história: notícias da II Conferência Nacional de Educação da $A B E$. Brasília, INEP, 2004, p.46.
} 
Recorrente no discurso médico-higienista do período, a representação da mulher pobre como um ser ignorante e incapaz de cuidar da saúde dos filhos e, nesse sentido, como a principal responsável pelos elevados índices de mortalidade infantil, figura como aspecto relevante na tese da educadora sanitária, que vê na disseminação de conhecimentos de puericultura, experiência que já vinha sendo desenvolvida em São Paulo sob sua direção, a possibilidade de reverter esse quadro. Redimidas pela puericultura, a mãe e a professora primária deveriam zelar pela saúde das crianças, assegurando a formação de homens fortes, saudáveis, produtivos e de virtuosas mães. ${ }^{21}$

Retomando a afirmação de Metchnikoff, que situa a higiene entre os ramos da moral aplicada, na medida em que "ensina ao indivíduo o modo de bem viver", ${ }^{22}$ a conferência proferida nesse mesmo evento pode ser lida como um apelo no sentido de que a instituição escolar se responsabilizasse pela educação sanitária das crianças, visando garantir a conquista da saúde pela correção dos "defeitos físicos"; a sua conservação, por meio da prática de hábitos saudáveis e a sua preservação, pela assimilação dos meios de evitar as moléstias infecto-contagiosas. Mesmo atribuindo papel central à escola na obra de inculcação de hábitos saudáveis, a autora não deixa de assinalar o papel reservado à mãe, advertindo:

mal comece o infante a adaptação à vida, mal desperte para o mundo, sejam seus primeiros atos norteados para a transformação em hábitos sadios, pela orientação da própria mãe. Há de ser ela, portanto, a orientadora, mais do que isso, a plasmadora, que há de imprimir na cera mole do cérebro infantil os primeiros hábitos dos quais

\footnotetext{
${ }^{21}$ Sobre as relações entre as educadoras sanitárias, as professoras e as mães, cf. LiMA, Ana Laura G. Entre a mãe e o "professor": as educadoras sanitárias. Seminário Docência, Memória e Gênero. São Paulo, FEUSP, 1997, pp.177-184.

${ }^{22}$ CASTRO, Maria Antonieta de. A escola e a educação sanitária. In: SILVA, Arlette Pinto O. (org.) Páginas da história... Op. cit., p.125.
} 
Educação sanitária

dependerá grandemente a felicidade ou infelicidade futura do seu filho. ${ }^{23}$

Concebendo a educação como possibilidade de transformação de atos em hábitos, por força da repetição constante, e considerando os hábitos saudáveis como base da saúde, uma vez que representavam uma barreira capaz de se antepor a tudo que pudesse ameaçar a integridade física do indivíduo, advoga, apoiando-se nas recomendações emanadas dos congressos internacionais e no exemplo das experiências de outros países, a centralidade da escola primária na educação sanitária da infância. Segundo ela,

esse aparelhamento é ideal para ser implantada a educação e ministrada a instrução sanitária; [assim] sobre a escola primária pesa, pois, uma enorme responsabilidade na grande obra do aperfeiçoamento da raça. Chamemo-la pois a ocupar o lugar que the compete na formação da consciência sanitária do cidadão. ${ }^{24}$

Com base nesses pressupostos, a educadora sanitária apresenta a grandiosa contribuição que a IESCS vinha oferecendo à obra de "regeneração da raça", por meio do trabalho nos centros de saúde e grupos escolares de São Paulo. Buscando a adesão dos professores e procurando construir consensos em torno da importância e urgência dessa obra, conclui com um apelo à colaboração desses profissionais no empreendimento de constituição de uma raça forte:

Professores: vede as possibilidades que vos oferece a escola na formação da consciência sanitária do cidadão. Não a desprezeis. Tomai-as como um dos objetivos para o qual deveis nortear vossa atividade. Crime seria o não fazer. A

${ }^{23}$ ID., IB., pp.125-126.

${ }^{24}$ ID., IB. 
hominicultura - cultura de homens - na frase de Waldomiro de Oliveira. Cultura de homens para o Brasil de amanhã, porque "the child is the father of man". Dos professores depende, em grande parte, que esse elo que liga as gerações passadas às gerações futuras seja retemperado na prática dos hábitos sadios, para que, rijo, como o aço, não se quebre, não se esfacele essa cadeia formidável que é a raça brasileira. Esse lema da educação sanitária diz: "A educação sanitária semeia. A raça colherá o fruto". ${ }^{25}$

A "regeneração da raça", concebida como eixo da atuação das educadoras sanitárias, figurará também como tema central das teses apresentadas por Maria Antonieta, na III Conferência Nacional de Educação e no $\mathrm{V}$ Congresso Brasileiro de Higiene, eventos que contaram com a participação de um significativo número de intelectuais envolvidos com a discussão de questões ligadas à educação e saúde. As práticas de educação sanitária desenvolvidas desde a mais tenra idade, no lar e na escola, apresentam-se, nessas duas teses, como possibilidades de intervir sobre a infância, corrigindo-lhe os defeitos, conservando-lhe a saúde e protegendo-a das moléstias infecciosas.

Organizada segundo uma estrutura bastante semelhante à da conferência proferida na $\mathrm{ABE}$, no ano anterior, a tese Escola e saúde defenderá o papel da escola como elemento central na formação da consciência sanitária e como "núcleo revigorador da saúde da população". Como epígrafe, podemos ler a seguinte afirmação, de autoria do médico argentino Olivieri:

A escola não deve formar intelectuais débeis e raquíticos mas deve proteger a saúde da nossa raça em formação tão heterogênea com suas amálgamas múltiplas, conseqüência

${ }^{25}$ ID., IB., p.128. 
Educação sanitária

fatal de nosso cosmopolitismo e país de imigração por excelência. ${ }^{26}$

O poder da instituição escolar no sentido de conter os riscos de degenerescência da raça, que poderiam resultar da entrada dos vários fluxos imigratórios, alicerça a tese de que a escola não deveria se constituir, tão somente, em centro da cultura intelectual da infância, cabendo-lhe transformar os "corpos enfermiços, rostos pálidos, organismos débeis" em "corpos fortes" $e$ "organismos robustos". ${ }^{27}$ No cumprimento desse desideratum, a educação sanitária figura como a "melhor arma de combate" de que poderia lançar mão a escola, com vistas a garantir a ampla difusão dos conhecimentos e a inculcação dos hábitos saudáveis, assegurando a formação da consciência sanitária, "base da estabilidade e segurança da nação". ${ }^{28}$

Diante da indagação acerca dos profissionais que deveriam se responsabilizar pela formação da consciência sanitária, a autora procura distinguir a experiência paulista daquilo que era desenvolvido em alguns países latino-americanos e europeus, nos quais essa atribuição era conferida a enfermeiras sanitárias ou visitadoras escolares. Procura, ainda, distinguir do que vinha sendo implementado no Rio de Janeiro, como parte da reforma promovida por Fernando de Azevedo, que organizara o Serviço de Higiene Escolar nomeando um corpo de enfermeiras escolares que deveria atuar na seleção das crianças consideradas débeis, correção dos maus hábitos, ensino das noções de higiene, além de visitas domiciliares para investigação sobre o estado social $e$

${ }^{26}$ AssociaÇÃo Brasileira de EduCAÇÃo. Annaes da III Conferencia Nacional de Educação. São Paulo, Departamento de Publicidade da Directoria Geral da Instrucção Publica, 1930.

${ }^{27}$ CASTRO, Maria Antonieta de. Escola de saude. In: AssociaÇÃo BRASILEIRA DE EdUCAÇÃo. Annaes da III Conferencia Nacional de Educação. São Paulo, Departamento de Publicidade da Directoria Geral da Instrucção Publica, 1930, pp.719-720.

${ }^{28}$ CASTRO, M.A. Escola de saude... Op. cit., p.720. 
sanitário da população. Segundo suas análises, as atribuições que cabiam às enfermeiras escolares circunscreviam-se ao campo da assistência ao escolar e da vigilância, enquanto que as educadoras sanitárias paulistas tinham "como tarefa primordial a propaganda sanitária", ${ }^{29}$ servindo de elo de ligação entre o centro de saúde e a escola, sem descurar da assistência sanitária ao escolar.

Como na tese apresentada no ano anterior, Maria Antonieta fala em nome da IESCS, procurando dar visibilidade à estrutura, funções e atividades desse órgão. Seu discurso confere especial relevo à atuação das educadoras sanitárias nas escolas, centros de saúde e domicílios. Retomando os vínculos com o magistério que marcaram a criação do curso de educadores sanitários em São Paulo, seu discurso visa produzir a idéia da superioridade desse corpo profissional em relação às enfermeiras ou visitadoras, acionando, para isso, o rol de habilidades adquiridas com o magistério. Educadora sanitária e professora mesclam-se, num discurso em que a especificidade da formação sanitária, conferida pelos estudos desenvolvidos junto ao Instituto de Hygiene, cede lugar aos conhecimentos pedagógicos:

De fato, quem melhor poderá cooperar para divulgação dos conhecimentos higiênicos, que a professora, acostumada a ensinar, senhora dos métodos e processos pedagógicos mais aperfeiçoados, conhecedora da psicologia do educando, capaz de adaptar o ensino ao grau de desenvolvimento de determinado grupo da população? (...) E quem melhor que a educadora sanitária - professora, poderá agir na Escola em favor da saúde do escolar? ${ }^{30}$

Assim, apresentando a experiência paulista, procura matizar as suas peculiaridades assinalando, sobretudo, o enfoque educativo assumido pelas iniciativas no campo da saúde pública. Por meio da enunciação das realizações da IESCS, seu discurso

${ }^{29}$ ID., IB., p.727.

${ }^{30}$ ID., IB., p.727. 
Educação sanitária

busca convencer os ouvintes do sucesso do empreendimento a cuja direção se lançara com afinco.

Reunindo as posições defendidas na tese Escola de saúde em torno de cinco conclusões, Maria Antonieta procura realçar o lugar da escola na formação da consciência sanitária da população e na "regeneração da raça brasileira". Como autoridade na matéria, apresenta a proposta de que a III Conferência recomendasse aos poderes públicos a difusão dos conhecimentos de higiene aos professores de todo o país. Discutidas as conclusões na Seção de Educação Sanitária, a recomendação da educadora sanitária figurará, no parecer final, num tom menos enfático e, quiçá, mais realista, circunscrevendo o oferecimento dos cursos de aperfeiçoamento para professores às capitais dos estados. ${ }^{31}$

O tema da "regeneração da raça" voltará a ser abordado na tese Puericultura e mortalidade infantil, apresentada no $\mathrm{V}$ Congresso Brasileiro de Higiene. Como epígrafe, podemos ler uma citação de Leredu, que indicia as preocupações eugênicas que perpassaram as iniciativas capitaneadas por Maria Antonieta, na direção da inspetoria:

Defendendo eficientemente a raiz da raça, tornado-a mais forte em número $e$ na qualidade, virilizando-a $e$ eugenisando-a, asseguramos ao nosso país um porvir mais belo e venturoso, servindo a um tempo à pátria e à causa da civilização. ${ }^{32}$

Lançando mão de gráficos, produzidos com base em dados estatísticos sobre mortalidade infantil na capital paulista e em dados sobre índices de abortos, partos prematuros e partos de termo, em mulheres com e sem assistência pré-natal, e do

${ }^{31}$ ID., IB., p.625

${ }^{32}$ CASTRO, Maria Antonieta de. Puericultura e mortalidade infantil. In: SoCIEDADE Brasileira de Higiene. Annaes do Quinto Congresso Brasileiro de Hygiene. Rio de Janeiro, 1930, p.327. 
cruzamento entre esses dados e o número de crianças atendidas nos centros de saúde, a educadora sanitária procura demonstrar a coincidência entre a implantação da inspetoria e a redução da mortalidade infantil. As iniciativas voltadas para o combate à mortalidade infantil são, nesse sentido, apresentadas como "remédios" contra esse "terrível desastre" que infelicitava a nossa raça. Tais iniciativas se desdobravam em dois eixos: um voltado para a assistência às gestantes, por meio do Serviço de Higiene Pré-natal e Infantil dos centros de saúde, com base no princípio de que "toda a higiene infantil tem sua raiz nos cuidados dispensados à gestante"; 33 o outro, orientado para a educação sanitária das mães. Foco da atuação da inspetoria, a educação sanitária abrangia palestras sobre puericultura, orientações sobre o preparo dos alimentos (ministradas na "Cozinha de dietética e de demonstrações") e a "Escola de mãezinhas", que oferecia cursos regulares de puericultura para alunas dos grupos escolares e para o público de mulheres que comparecia aos centros de saúde. Por meio desses procedimentos, procurava-se fazer "calar fundo no espírito de cada paciente que daí sai levando da palavra amiga a mensagem de saúde de seu filho". ${ }^{34}$

Metaforizado como "palavra amiga", o discurso prescritivo das educadoras sanitárias procura alcançar a população feminina nos mais diferentes estágios da vida, fazendo incidir sobre ela o peso da responsabilidade sobre a vida e a saúde das crianças pequenas. Das jovens estudantes dos grupos escolares às gestantes $e$ mães, as mulheres figuram como alvo dessa "cruzada regeneradora" que, utilizando-se da difusão dos conhecimentos de higiene e puericultura como principal "arma de combate", procura disciplinar o cotidiano das relações entre as mulheres-mães $e$ os seus filhos, nos seus mais diversos aspectos. Vários foram os meios utilizados para fazer chegar essa "palavra amiga" às mulheres, os quais não se limitaram aos espaços institucionais dos centros de

${ }^{33}$ ID., IB., p.328.
${ }^{34}$ ID., IB., p.330. 
Educação sanitária

saúde e grupos escolares, mas adentraram o próprio lar, por intermédio das visitas domiciliares, feitas em geral nos primeiros dias de vida da criança, da distribuição de impressos, publicação de artigos e, ainda, de conferências e palestras difundidas por meios modernos como a rádio-telefonia, que possibilitava que essa "voz amiga" atingisse um amplo contingente de mulheres.

Se várias eram as formas e diversificados os meios dos quais se podia lançar mão nesse empreendimento, mais uma vez é a escola que se impõe como locus privilegiado para a divulgação desses preceitos, posição essa referendada pelo recenseamento das experiências internacionais, bem como das iniciativas que vinham sendo encetadas no Rio de Janeiro. Nesse sentido, indaga a autora:

E por que não estender tal obra de divulgação a outros aparelhamentos, à Escola, por exemplo, que deve ser a grande divulgadora da Puericultura? ${ }^{35}$

Tal é a importância atribuída à puericultura, que Maria Antonieta defende a urgência de se quebrarem as barreiras representadas pelos preconceitos e implantar o seu ensino em todas as escolas primárias e colégios do país, argumentando em torno da importância da presença de tal conteúdo na formação dos professores. Como se pode observar, a formação dos professores figura como uma questão recorrente na sua produção. Nesse sentido, nessa tese, como na que apresentou no mesmo ano na conferência da $\mathrm{ABE}$, vamos encontrar a proposição de conteúdos curriculares que deveriam compor a formação dos futuros mestres: a higiene e a puericultura - novos conteúdos revestidos de velhos valores em relação à mulher. ${ }^{36}$

${ }^{35}$ ID., IB., p.332.

${ }^{36}$ Analisando as propostas que, a partir do final do século XIX, passaram a defender, com base nas idéias positivistas e cientificistas, a introdução de disciplinas como puericultura, psicologia e economia doméstica no currículo dos cursos femininos, Guacira Louro chama a atenção para a permanência das 
A atuação de Maria Antonieta de Castro, no âmbito desse órgão novo que, atuando em múltiplas frentes, constituía a infância como objeto de intervenção privilegiado, fazendo da mulher, mãe e professora, o alvo de um conjunto de prédicas $e$ práticas que procuravam redimi-la da suposta ignorância, garantindo a geração de filhos fortes, robustos e ordeiros, para o engrandecimento da pátria. No centro da "cruzada de regeneração da raça" a que se lançaram as educadoras sanitárias, vemos surgir a figura da mulher identificada à maternidade, a mulher-mãe, anjo e demônio, salvação ou condenação da raça. Lado a lado com as imagens da mulher, as representações de uma infância frágil, indefesa e moldável depositada em suas mãos.

\section{Fiéis colaboradoras?}

Respeitada por sua atuação, Maria Antonieta foi laureada com vários prêmios e recebeu um significativo número de homenagens, ao longo de sua vida, ${ }^{37}$ que sugerem a consonância das suas iniciativas com os objetivos de ordenação e controle social que perpassam a reforma sanitária de 1925 - articulada em torno do intento de formação da consciência sanitária individual, visando assegurar que os indivíduos aprendessem a se autogovernar, responsabilizando-se pela sua própria saúde.

Em 1962, por ocasião da solenidade de aposentadoria $e$ entrega do prêmio Jubileu de Ouro, pelos 50 anos de serviços prestados ao Estado, foi instituído, em sua homenagem, o dia 11

"velhas concepções relativas à essência do que se entendia por feminino" nas justificativas para a difusão desses novos conceitos científicos. Assim, é visando orientá-la no cumprimento do seu destino de mãe, responsável pela higienização da família e pela construção da cidadania dos jovens, que a educação da mulher se justificaria. LOURO, G.L. Mulheres na sala... Op. cit., p.448.

${ }^{37}$ Em 1927, foi premiada no concurso literário Tarde da Criança, com Papagaio Louro, livro de contos infantis para a divulgação de hábitos de higiene; em 1929, foi laureada pela Liga Brasileira de Higiene Mental, por um trabalho sobre o alcoolismo e, em 1950, pela Standard Oil Company of Brazil, como pioneira em educação sanitária em São Paulo. 
Educação sanitária

de junho, data do seu aniversário natalício, como Dia do Educador Sanitário. O discurso proferido pela deputada Conceição Costa Neves, autora do projeto de criação dessa data comemorativa, oferece importantes elementos para a análise das representações produzidas socialmente em relação a esse grupo profissional, constituído predominantemente por mulheres. Procurando realçar as qualidades da educadora sanitária, a parlamentar enfatizou o "carinho e dedicação" que marcaram a sua atuação, afirmando: "sua carreira é um exemplo. Fez do trabalho um apostolado". Justificando seu projeto, destacou o "espírito de solidariedade e de compreensão humana" como requisitos essenciais no desempenho das "missões" a que eram chamadas as educadoras sanitárias e como elementos que as distinguiam dos demais profissionais:

É a classe dos educadores sanitários uma categoria profissional hoje indispensável a todo serviço de saúde pública. Profissionais polivalentes, que além de serem educadores são a um tempo enfermeiros $e$ assistentes sociais, os educadores sanitários, por força de sua própria formação, imprimem a seu trabalho o calor humano necessário a toda realização social, especialmente a que diz respeito à saúde pública. ${ }^{38}$

Semelhantes argumentos seriam utilizados pela deputada, em outra ocasião; desta vez para defender, junto à Assembléia Legislativa, a indicação do nome da educadora sanitária para o quadro de Cidadão Emérito, em 1965. Na justificativa que fez ao projeto de outorga do título, a parlamentar destacou a atuação de Maria Antonieta como pedagoga, higienista e pesquisadora, considerando-a como "a personificação da mulher que se

\footnotetext{
${ }^{38}$ Homenagem a Maria Antonieta de Castro quando da instituição do "Dia do Educador Sanitário" na $100^{a}$ Sessão Ordinária da Assembléia Legislativa do Estado de S. Paulo, publicada no Diário Oficial, de 13 de junho de 1962. Centro de Memória da Saúde Pública/Faculdade de Saúde Pública/USP.
} 
entregou à luta contra a mortalidade infantil, à educação sanitária, à higiene". Na concepção da deputada, a outorga do título se configurava num

imperativo de carinho $e$ admiração que merece a mulher brasileira que faz da luta trabalho e na execução de seu trabalho sabe elevar-se acima do comum dos mortais. ${ }^{39}$

Pautados nos ideais religiosos de "vocação", "apostolado", "missão", "renúncia" e "abnegação" que, em sua leitura, orientavam a atuação de um grupo de profissionais polivalentes, a um só tempo, educadores, enfermeiros e assistentes sociais, os argumentos acionados em momentos distintos se articulam no sentido de marcar a vinculação da profissão a um conjunto de profissões tidas como femininas, na medida em que exigiam características e habilidades supostamente inatas às mulheres, que as predispunham a atividades ligadas ao ato de cuidar.

Elogiando-a pela sua atuação no cargo de educadora sanitária chefe, Almeida Junior, na qualidade de médico-chefe do Serviço de Higiene e Educação Sanitária Escolar do Departamento de Educação, dirigiu-lhe, em 1934, as seguintes palavras:

quanto a V. S., nome já feito em matéria de educação sanitária, e, cujo valor, era do meu conhecimento, tive, exatamente, o que esperava, isto é, um apoio inteligente e integral às minhas iniciativas, uma execução fiel às medidas combinadas, e, ainda, continuadas e felizes sugestões, de incontestável benefício para o serviço. ${ }^{40}$

${ }^{39}$ Cidadão Emérito. Projeto de outorga do título a Maria Antonieta de Castro na Assembléia Legislativa do Estado de São Paulo pela deputada Conceição da Costa Neves, em 12/04/1965. Centro de Memória da Saúde Pública/Faculdade de Saúde Pública/USP.

${ }^{40}$ Maria Antonieta de Castro. Centro de Memória da Saúde Pública/Faculdade de Saúde Pública/USP. 
Educação sanitária

Registro do reconhecimento do trabalho da educadora sanitária, as palavras de Almeida Junior são reveladoras das representações dos médicos em relação a esse corpo profissional, constituído, em sua grande maioria, de mulheres e do qual se esperava o "apoio inteligente e integral", "a execução fiel" e, quiçá, "felizes sugestões"; representações que não se distanciam do ideal de mulher formulado por Rousseau, no século XVIII, o qual reservava às mulheres as tarefas de colaboradoras $e$ assistentes dos "homens de ciência". ${ }^{41}$

Referindo-se à presença das mulheres no magistério $e$, mais especificamente, nos cargos da administração educacional, afirmava Almeida Júnior, em 1933, na Associação de Professores de São Paulo:

A mulher insinuou-se maneirosamente no ensino primário $e$ foi aos poucos afastando o homem. As leis e as praxes a mantiveram arredada por muito tempo da administração, alegando-se como elementos irremovíveis os excessos de sua afetividade $e$ a insegurança de seu temperamento. Mas a resistência cedeu. ${ }^{42}$

A leitura do seu testemunho em relação à atuação de Maria Antonieta como educadora sanitária chefe leva a indagar até que ponto essa resistência terá efetivamente cedido. O contraponto entre os dois discursos ajuda a interrogar acerca dos limites em que se tentou conter a sua atuação na administração dos rumos da educação sanitária, mas também problematizar a forma como ela encarou tais limites, permitindo interrogar até que ponto se ateve ao "fiel cumprimento" das normas traçadas pelos mentores da reforma.

${ }^{41}$ TOSI, Lucía. Mulher e Ciência. A revolução científica, a caça às bruxas e a ciência moderna. Cadernos Pagu (10), Campinas-SP, Núcleo de Estudos de Gênero-Pagu/Unicamp, 1998, pp.369-397.

42 ApudLouro, G.L. Mulheres na sala... Op. cit., p.452. 
A trajetória de Maria Antonieta de Castro permite, nesse sentido, acompanhar o processo de institucionalização da educação sanitária, ao mesmo tempo em que oferece elementos para uma leitura das representações que presidiram a inserção feminina nesse novo campo de atuação. Nas justificativas para a escolha das professoras, produzidas à época da criação do curso, é recorrente a afirmação de ter sido essa solução engendrada em função da falta de enfermeiras que, a exemplo da experiência norte-americana, pudessem ser designadas para essa tarefa. As análises retrospectivas, embora retomando essa questão, procurarão minimizá-la, pondo em destaque as vantagens da formação pedagógica e constituindo as educadoras sanitárias em "pivô do triunfo" da reforma dos serviços de saúde pública. ${ }^{43}$

Além da formação pedagógica, um outro elemento teria sido decisivo na escolha das professoras: a possibilidade de ampliação do raio de influência sobre as crianças e suas famílias, pela penetração no ambiente doméstico. Aos médicos paulistas, que capitanearam a reforma sanitária de 1925, a experiência norte-americana ensinara que algumas atribuições que cabiam a esses "auxiliares de saúde" eram tarefas eminentemente femininas. Assim, referindo-se à atuação das educadoras sanitárias como visitadoras, Paula Souza e Borges Vieira anotariam os ensinamentos norte-americanos:

Os visitadores, que até os fins do século XIX eram representados pelos enfermeiros, geralmente homens, foram tomando outra feição: a de mensageiros de higiene e das medidas preventivas, recebendo para isso instrução geral e técnica, de caráter principalmente higiênico-social. E ainda: dada a maior facilidade de sua ação nos lares, deu-

${ }^{43}$ SouzA, Geraldo Horácio de Paula. Centros de saúde. Centro de Memória da Saúde Pública/Faculdade de Saúde Pública/USP, s.d., p.14. 
Educação sanitária

se preferência às mulheres, às visitadoras, sendo afastados desta tarefa os homens. ${ }^{44}$

Consideradas como peça chave na reforma dos serviços de saúde pública operada em São Paulo, as educadoras sanitárias reuniam, assim, as vantagens da formação pedagógica e a facilidade de penetrar nos lares, tematizando com sua "palavra amiga" aspectos que iam da concepção aos modos de cuidar e educar as crianças; qualidades às quais se somava uma outra característica também considerada feminina: a capacidade de atuar como eficientes colaboradoras dos "homens de ciência", submetendo-se a salários inferiores e condições de trabalho, em geral, adversas. Como evidenciam as considerações de Almeida Junior, este teria sido um aspecto da maior importância na atuação de Maria Antonieta junto à IESCS. A função auxiliar a que são chamadas é também destacada pelos paladinos da reforma, quando afirmam que:

Os médicos e engenheiros constituem os principais elementos superiores dos serviços de saúde pública. (...)

É óbvio, porém que, tal qual num exército, não se compreende um efetivo composto apenas de oficiais, também na saúde pública, os funcionários técnicos graduados necessitam ser assistidos por auxiliares em número suficiente e com preparo adequado, constituído pelas enfermeiras de saúde pública, educadoras ou visitadoras sanitárias, técnicos de laboratório, inspetores ou guardas etc., para não falarmos no pessoal burocrático, não especializado, atributos de qualquer organização. ${ }^{45}$

${ }^{44}$ SouZA, Geraldo Horácio de Paula e VIEIRA, Francisco Borges. Centro de Saude "eixo" de organização sanitaria. Boletim do Instituto de Hygiene de São Paulo (59), São Paulo, Imprensa Official do Estado, 1936, p.24.

${ }^{45}$ ID., Formação de técnicos para os Serviços de Saúde Pública. Revista de Higiene e Saúde Pública. (1) 1948, pp.34-5. 
Como num exército, esse corpo profissional, composto predominantemente de mulheres, sob a direção de uma mulher, deveria assumir o lugar que, segundo os articuladores da reforma, hierarquicamente lhe cabia, cumprindo o papel de colaborar para o sucesso das intervenções no campo da saúde, ainda que sem um vínculo profissional claramente definido, já que o cargo de educadora sanitária só foi criado oficialmente em 1938, quando um contingente superior a 200 profissionais já havia sido formado. Dentre as responsabilidades que foram chamadas a assumir, a maior delas talvez fosse a de convencer outras mulheres, professoras primárias, mães e futuras mães, sobre o valor da adesão a um novo modo de vida e sobre o seu papel na inculcação de hábitos saudáveis nas crianças, fossem elas os alunos ou os próprios filhos, por meio dos quais se tornariam fortes, robustos, ordeiros, garantindo um futuro alvissareiro para a pátria.

A trajetória de Maria Antonieta de Castro não parece confirmar o papel secundário que lhe é relegado nas análises dos médicos que capitanearam a reforma ou que foram chamados a assumir postos de comando no âmbito da inspetoria. Atuando nas múltiplas frentes em que se desdobrou a ação desse órgão, criando uma associação de classe, participando ativamente de uma entidade filantrópica em cuja criação teve um papel fundamental, desenvolvendo pesquisas, publicando, viajando, participando de congressos educacionais e médicos, essa educadora sanitária, certamente, não se limitou ao "apoio inteligente e integral" às iniciativas dos seus superiores, nem tampouco à "execução fiel às medidas combinadas".

Os objetivos de divulgação de um novo modo de vida à população parecem ter orientado a atuação das educadoras sanitárias durante um largo período. As representações sobre a infância e sobre o papel da mulher no cuidado com os pequenos parecem ter se alinhado na produção de uma auto-representação em que as educadoras sanitárias figuram como 
Educação sanitária

uma espécie de anjo da guarda da saúde do escolar, desempenhando, segundo o caso se lhe apresenta, as funções de professora, de enfermeira, de assistente social. ${ }^{46}$

$\mathrm{Na}$ confluência dessas profissões, as quais foram se constituindo como espaços de atuação profissional predominantemente femininos, foi se produzindo uma autorepresentação da educadora sanitária e do seu papel, que compõem a imagem de um "anjo da guarda" a zelar pela educação, pela saúde e pela moral, nas escolas, ruas e casas. "Dos meandros do ler e escrever à cruzada da saúde", essas mulheres parecem definir a sua trajetória como momentos de um "apostolado" forjado com base na inabalável crença no poder da educação na superação dos problemas nacionais. Nesse "apostolado", mescla-se, ao papel empreendedor de mulheres como Maria Antonieta, o recorrente apelo ao despojamento feminino, configurando a educadora sanitária como "anjo da guarda" que, em sua vigília incessante, chama a si a responsabilidade de cuidar da família e da infância, da "louca mocidade", das "jovens e donzelas".

A análise da trajetória dessa educadora sanitária permite, nesse sentido, problematizar aspectos significativos da constituição de um projeto de nação, alicerçado sobre os ideais de "regeneração da raça", no qual a educação e a saúde figuram como elementos indissociáveis, oferecendo pistas para a indagação sobre o papel das mulheres na articulação desse projeto. As múltiplas facetas da sua atuação possibilitam tensionar o mito da passividade feminina, por meio do qual se vem sistematicamente silenciando a presença das mulheres na história.

${ }^{46}$ CASTRO, Maria Antonieta de. A educação sanitária nas escolas. In: RiCARDO, Aristides et alii. Educação sanitária. Divulgação de conhecimentos básicos de higiene para professores e normalistas. São Paulo, Diretoria do Serviço de Saúde Escolar, 1947, p.100. 